\title{
A criação de histórias no centro de convivência: um encontro espontâneo por meio do psicodrama
}

DOI: https://doi.org/10.5935/1984-9044.20200016

\author{
Karine de Almeida Aderaldo ${ }^{1}$ \& Giovana Pelattí - Universidade Estadual de \\ Campinas (UNICAMP)
}

Resumo: O presente artigo irá descrever a experiência de construção de uma Oficina de Criação de Histórias num Centro de Convivência da cidade de Campinas. Tal experiência se desenvolveu a partir do trabalho de uma residente de saúde mental, tendo como embasamento teórico o Psicodrama, sobretudo o conceito de espontaneidade. Através do ato de criar histórias foi possível perceber que os frequentadores puderam experenciar suas espontaneidades de outras formas. Sugere-se que o Centro de Convivência seja um espaço que se volte não só para a inclusão e promoção de saúde, mas também para a espontaneidade e protagonismo de seus usuários.

PALAVRAS-CHAVE: saúde mental, centro de convivência, psicodrama, oficina terapêutica.

\section{A HISTORIES CRIATION IN THE CONVIVENCE CENTER: A SPONTANEOUS MEETING THROUGH PSYCHODRAMA}

\begin{abstract}
This article will describe the experience of building a Story Creating Stories Workshop in a Living Center in the city of Campinas; such experience was developed from the work of a mental health resident, having as theoretical basis the Psychodrama, especially the concept of spontaneity. Through the act of creating stories it was possible to realize that the frequenters could experience their spontaneity in other ways. It is suggested that the Living Together Center should be a space that turns to inclusion and health promotion, but also to the spontaneity and protagonism of its users.
\end{abstract}

KEY WORDS: mental health, living center, psychodrama, therapeutic workshop.

1 ORCID: https://orcid.org/0000-0002-5012-3397

${ }^{2}$ Artigo baseado no Trabalho de Conclusão de Curso das autoras, sob orientação de Bruno Ferrari Emerich 


\section{Sobre o Centro de Convivência e suas oficinas}

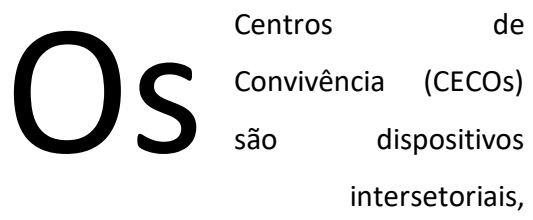

inseridos e articulados a um território, que têm como objetivo a promoção de espaços de convívio e participação social para todas as pessoas do território, sobretudo aquelas que de alguma forma vivenciam algum tipo de exclusão (Ferigato, Carvalho e Teixeira, 2016).

Como pontuam Aleixo e Lima (2017), os CECOs se diferenciam de grande parte dos equipamentos de saúde por conceber a saúde para além da doença e sua remissão de sintomas, e assim propor diferentes estratégias de ações, como oficinas, grupos e ações comunitárias, promovendo a convivência que produz inclusão por meio de cuidado e saúde em "defesa da vida" (Ferigato,Carvalho e Teixeira, 2016, p. 87).

Por ter outra concepção e atuação na saúde, esse serviço é palco de importante ressignificação do processo saúde-doença-intervenção ao criar "novas perspectivas no encontro entre profissionais e usuários, além de estabelecer uma relação com a comunidade especialmente a partir de suas potências e não apenas a partir de suas fragilidades ou riscos identificados" (Ferigato, Carvalho e Teixeira, 2016, p. 92).

Uma das principais formas de cuidado do Centro de Convivência junto aos usuários são as Oficinas (Galletti, 2004), por meio das quais há promoção do encontro entre quem ali está, além da criação de condições favoráveis para a inserção e integração.

As oficinas são dispositivos terapêuticos de caráter múltiplo e heterogêneo, ou seja, "composto[s] de naturezas diversas, numa multiplicidade de formas, processos e linguagens" (Galletti, 2004, p. 24), feitos de experimentações múltiplas, com intersecção de vários 
A CRIAÇÃO DE HISTÓRIAS NO CENTRO DE CONVIVÊNCIA: UM ENCONTRO ESPONTÂNEO POR MEIO DO PSICODRAMA

campos e saberes, com o propósito de modificar antigas práticas no contexto da Reforma Psiquiátrica. Funcionam, assim, como um "dispositivo institucional propiciador da invenção de novas relações, de convivência entre sujeitos marcados por histórias de 'exclusão' e marginalização e destes com o restante da 'população comum'" (Galletti, 2004, p.57).

\section{A proposta de uma nova Oficina}

Isso posto, o conhecimento da experiência descrita neste trabalho vai ao encontro do que Bondía (2002) compreende como "experiência": algo que nos passa, nos acontece, nos toca, e o "saber da experiência", que se dá na relação entre o conhecimento e a vida humana. $O$ saber da experiência acontece ao longo da vida à medida que se vai respondendo aos fatos e ao modo como dar sentido ao que acontece.

A experiência a seguir relatada ocorre como componente da formação da Residência em Saúde Mental, que ocorreu em um Centro de Convivência de uma cidade de grande porte do interior de São Paulo. Tem como características a articulação com outros equipamentos de cultura e assistência social do território mais próximo, e a maior parte da população que frequenta esse espaço está acima dos quarenta anos de idade.

Atuar como psicóloga residente em um Centro de Convivência me exigiu repensar a prática constantemente, tanto pelo outro formato de oferta, diferente dos "tradicionais" compreendidos como os próprios do núcleo da Psicologia, quanto na amplitude de olhares que exigem esse dispositivo, que demandam atenção e ação para que alcance fazer o que se propõe.

O estar no CECO faz pensar não só nos outros serviços do território, mas também leva à reflexão sobre o próprio serviço: Em quais oficinas estão inseridos os usuários? O que os faz estar em uma e 
A CRIAÇÃO DE HISTÓRIAS NO CENTRO DE CONVIVÊNCIA: UM ENCONTRO ESPONTÂNEO POR MEIO DO PSICODRAMA

não em outra? Quem são esses usuários? Que histórias eles contam? Como os usuários criam nas oficinas? Ou melhor, as oficinas estão sendo espaço em que as pessoas conseguem criar? E que espaços eles ocupam nessas oficinas?

Tomada por esses questionamentos, foi proposta a Oficina de Criação de Histórias, um lugar em que os frequentadores pudessem criar, compartilhar e vivenciar as histórias que desejassem. Essa oficina foi pensada a partir da percepção da ausência de um espaço em que houvesse mais espaço para cada um narrar sobre si e ouvir mais

\section{O Psicodrama}

A criação do psicodrama como uma abordagem que se situa entre a ciência e a arte è um método que estuda as verdades existenciais através da ação (tradução da palavra drama, em grego), e se deu como forma de reagir aos métodos individualistas e mais racionais que predominavam na época de Moreno (Ramalho, 2010). dos outros, tendo por sustentação o norte teórico em Psicodrama da primeira autora. Tal Oficina ocorria semanalmente, no próprio espaço do Serviço, e aconteceu entre os meses de maio e dezembro de 2019. Participaram ao todo cerca de vinte usuários e, em cada encontro, a média era de seis pessoas.

Portanto, o objetivo deste trabalho é apresentar e discutir o funcionamento da Oficina Criação de Histórias, com base no Psicodrama, discutindo temas como espontaneidade e protagonismo.

Moreno (1975) desenvolve a teoria psicodramática tendo como ponto de partida a concepção de indivíduo como um ser em relação, ou seja, um indivíduo social, já que desde o seu nascimento está inserido em uma sociedade, necessitando dela para sobreviver (Gonçalves, Wolff e Almeida, 1998). 
A CRIAÇÃO DE HISTÓRIAS NO CENTRO DE CONVIVÊNCIA: UM ENCONTRO ESPONTÂNEO POR MEIO DO PSICODRAMA

Dessa forma, a identidade surge dos papéis desempenhados na sociedade, uma vez que papel "pode ser definido como uma unidade de experiência em que se fundiram elementos privados, sociais e culturais" (Moreno, 1975, p.53).

Moreno concebe o humano como alguém que tem como recursos inatos a espontaneidade, a criatividade e a sensibilidade. Ele entende que o indivíduo desde o nascimento traz fatores que têm a potência de influenciar de forma favorável seu desenvolvimento, mas que isso pode não acontecer devido a ambientes ou condições que impeçam esse processo. E, caso isso não aconteça, a recuperação desses fatores vitais será feita por meio de novas relações afetivas e da ação transformadora sobre o meio. A capacidade de o humano ser naturalmente espontâneo e criativo é chamada de Fator E (Gonçalves, Wolff e Almeida, 1998).

Durante o decorrer de sua vida, o sujeito se depara com as expectativas sociais impostas sobre como deve se dar ou não desempenho de um determinado papel; e, como Oliveira (2016) pontua, esse ideal pode por um lado ensinar sobre o desempenho desse papel e, por outro, representar uma barreira.

Conserva cultural é o termo criado por Moreno para falar dessas tradições e costumes que se encontram cristalizados em uma determinada cultura. Essas conservas podem constituir um obstáculo ao desenvolvimento da espontaneidade, que deve ser o ponto de partida da criatividade. Para ele, a conserva cultural se propõe a ser o produto acabado, adquirindo uma qualidade quase sagrada. Assim sendo, o humano deve se libertar da submissão às conservas culturais e cultivar o estado espontâneo-criativo (Moreno, 1984 e Ramalho, 2010), o que não significa negálas. A atuação espontânea e criadora é esse passo a mais, dado a partir do que já foi criado (Martin, 1996).

A espontaneidade é, de maneira operacional, como a resposta adequada para uma situação nova, ou uma nova resposta para uma situação antiga (Moreno, 1975).

A patologia da espontaneidade se caracteriza pelo excesso de impulsividade, pela carência, falsidade 
A CRIAÇÃO DE HISTÓRIAS NO CENTRO DE CONVIVÊNCIA: UM ENCONTRO ESPONTÂNEO POR MEIO DO PSICODRAMA

ou desadaptação dessa espontaneidade, em um determinado papel, que se encontra estático, ou seja, cristalizado (Ramalho, 2010).

Nesse sentido, Moreno propõe uma "revolução criadora" através do psicodrama, que se dará pelo resgate da espontaneidade perdida no ambiente afetivo e no sistema social. $\mathrm{O}$ objetivo da atuação psicodramática, então, é superar a repetição, as conservas culturais, produzindo Encontros (Ramalho, 2010).

No quesito desses Encontros, Moreno traça o importante conceito de tele. 0 fator tele refere-se à capacidade de distinguir objetos e pessoas sem distorcer seus papéis essenciais, e pode ser considerada uma forma de percepção interna mútua e verdadeira entre os indivíduos.

Moreno aponta que transferência, ou o fator transferencial, seria então a ausência de tele, em que há uma percepção equivocada ou distorcida do outro; seria a patologia do fator Tele (Gonçalves, Wolff e Almeida, 1998).

Nas relações em que há a percepção télica, há a empatia de via dupla, de reciprocidade, o Encontro. Essas relações télicas são movidas pela espontaneidade no aqui e agora e pelo Encontro (Ramalho, 2010). O Encontro Existencial é convite para a convivência simultânea, é o momento de criação e de espontaneidade, é a reunião, o confronto de corpos, a percepção do outro, o penetrar no sentimento do outro (Ramalho, 2010; Gonçalves, Wolff e Almeida, 1998).

A patologia dos sujeitos pode se dar em torno do adoecimento da espontaneidade e da criatividade, que ocasionam o adoecimento do papel e do grupo.

O adoecimento do papel ocorre em função das imposições sociais de funções, ou papéis indesejados, ou seja, o adoecer que contribui para a vivência do papel de forma patológica se dá em razão das circunstâncias externas limitantes (Martín, 1996). Já o adoecimento do grupo tem relação com a tele e de como as relações dentro de um mesmo grupo ocorre: se há escolha e aceitação recíprocas. 
A CRIAÇÃO DE HISTÓRIAS NO CENTRO DE CONVIVÊNCIA: UM ENCONTRO ESPONTÂNEO POR MEIO DO PSICODRAMA

Para recuperar a saúde da espontaneidade, é fundamental um resgate da flexibilidade, da liberdade, do poder e da criatividade. É tornar esse sujeito capaz de reagir, liberando-o dos sentimentos de resignação e impotência que estão presentes na forma que ele até então lida com as conservas culturais. A saúde do desempenho de papéis diz respeito à própria saúde da espontaneidade.
O resgate desse estado saudável poderá acontecer na situação psicodramática, que pode permitir a recuperação do domínio e o poder de recriação do sujeito, que estará experimentando novos papéis e recriando os antigos.

Dessa forma, o objetivo da terapêutica psicodramática será o tratamento das relações adoecidas (Martín, 1996).

\section{A prática psicodramática}

A prática psicodramática se estrutura nos contextos, instrumentos e etapa (Gonçalves, Wolff e Almeida, 1998).

O contexto é a ligação das vivências privadas e coletivas dos sujeitos que se relacionam em um dado espaço-tempo e pode ser social, grupal e psicodramático.

O contexto social é definido pela realidade, tal como é, pelo tempo cronológico e pelo espaço geográfico e concreto que compõem a realidade social, que terá, enquanto comunidade ou sociedade, características próprias no tocante à cultura, economia, política e, portanto, a leis e regras próprias.

O contexto grupal, que está contido em um grupo formado por situações definidas e objetivos específicos, é constituído pelo tempo cronológico dentro de um intervalo estabelecido previamente e pelo espaço geográfico, escolhido e delimitado.

O contexto dramático, por sua vez, ocorre na realidade do imaginário, da 
INTERAÇÕES SOCIAIS DE CRIANÇAS DE TRÊS A QUATRO ANOS EM INSTITUIÇÃO

DE EDUCAÇÃO INFANTIL

fantasia. É o "como se", definido por um tempo subjetivo e por um espaço virtual construído sobre o espaço concreto, marcado.

Em relação aos instrumentos, os autores definem que são os meios aplicados no método e nas técnicas psicodramáticas: cenário, protagonista, diretor, egoauxiliar e público ou plateia.

O cenário, ou palco, em termos gerais, é onde ocorre a ação dramática, um espaço móvel de muitas dimensões, sem convenções estabelecidas, sendo necessário, entretanto, que todos partam delas, por exemplo, o que representa determinada coisa naquele cenário específico.

O protagonista é o sujeito que emerge para a ação, que pode ser tanto um indivíduo quanto um grupo.

O diretor é aquele que coordena a sessão e tem como funções a direção específica da cena, em que vai cuidar da preparação do grupo para a ação, ter sensibilidade para procurar, com os integrantes, a melhor direção para o grupo e manter a tele com o público; estar atento aos sentimentos, emoções e pensamentos que ocorrem em cena; e compartilhar o que compreendeu do que foi vivido no momento com o protagonista.

Knobel (2012) afirma que a ação do diretor pode ter diferentes enfoques. Pode ter como vértice o protagônico, que se dará a partir de uma sequência de cenas que caminham para uma cena principal que explicita o conflito central do grupo; ou pode se guiar em função da espontaneidade, em que privilegia criações conjuntas flexíveis, criativas e momentâneas; ou então pode voltar-se para um foco relacional, a respeito das rejeições e aproximações entre as pessoas desse grupo.

O quarto instrumento, o ego-auxiliar, por sua vez, é aquele que interage em cena com o protagonista, que representa os papéis que lhe são solicitados e também comunica ao diretor aspectos que esse porventura não tenha percebido por não estar interagindo diretamente com o protagonista.

E o quinto é o público, conjunto dos demais participantes que não estiverem diretamente em cena. 
INTERAÇÕES SOCIAIS DE CRIANÇAS DE TRÊS A QUATRO ANOS EM INSTITUIÇÃO

DE EDUCAÇÃO INFANTIL

As fases dos métodos de ação são: aquecimento, dramatização e o compartilhar.

O aquecimento é a fase inicial de preparação do grupo e do protagonista e ocorre em duas fases: o inespecífico, que abrange as falas, os movimentos e as expressões iniciais que preparam o grupo, e o específico, que é mais voltado para o trabalho que será feito.

A dramatização é o desenvolvimento da cena em si, que possibilita ao indivíduo/grupo uma nova organização dos mundos interno e externo. A dramatização é, portanto, a grande máxima dos métodos de ação. Nesse momento é criada a realidade suplementar, que gera catarse de integração, "na qual todos os membros do grupo reaprendem sobre si, sobre suas relações, e a espontaneidadecriatividade de cada um é colocada a serviço do bem-estar coletivo" (Malaquias, 2012, p. 24).

A terceira fase é o compartilhar, momento dedicado à expressão de emoções sobre o que foi vivido e, por meio desses relatos, acontecem as identificações e o desenvolvimento da empatia entre os participantes.

\section{A Oficina de Criação de Histórias}

A Oficina iniciou-se com o nome de Contação de Histórias e tinha como funcionamento básico o seguinte: em cada encontro uma pessoa trazia uma história de que gostasse. Não importava

\footnotetext{
${ }^{3}$ Todos os nomes utilizados neste artigo são fictícios.
}

se fosse texto, música, figura; autoral ou não.

Teve dia que $\mathrm{Nise}^{3}$ trouxe sua música favorita, mas ficou chateada porque outra pessoa fez críticas à letra. Já na semana seguinte, imaginamos sobre 
A CRIAÇÃO DE HISTÓRIAS NO CENTRO DE CONVIVÊNCIA: UM ENCONTRO ESPONTÂNEO POR MEIO DO PSICODRAMA

como seria a experiência de um esqueleto vivo na cidade, e isso levou a uma conversa sobre o que cada um acreditava sobre a morte.

Um dia, Ziraldo tinha ficado responsável por levar uma história, só que ele se esqueceu de fazer antes, como esquecia outras coisas também. Como outras pessoas não apareceram para Oficina, me ofereci para fazer com ele, se quisesse. Aceitou e construímos juntos. Criamos uma história com um tema que falava bastante em outros espaços, além da Oficina, e diante de um dilema enfrentado pelo seu personagem principal, ficou paralisado, pois se identificou com a situação. Pensou na sua vida, nos seus próprios dilemas e chorou. Conseguimos conversar sobre isso e voltamos para a história. O dilema foi resolvido, guardamos aquela história na memória do computador e na nossa também.

Depois de um tempo, pensamos se a Oficina tinha o melhor nome. Talvez "Contação de Histórias" não traduzisse tudo que realmente era, e eis que aconteceu o seguinte diálogo:
“-Vocês acham que esse nome pode acabar confundindo as pessoas que só escutam o nome da Oficina?

- Eu acho que sim, porque essa Oficina é bem diferente da que tinha aqui antes no CECO e não é só contar historinha pra criança.

- E o que vocês acham do nome "Oficina de Histórias"?

- Eu acho que fica melhor "Oficina de Criação de Histórias".

- Será que esse nome não passa a impressão que as pessoas vão aprender a criar histórias aqui? $\mathrm{Ou}$ que só pode vir quem já consegue criar?

- Não... As pessoas vão ver que aqui vai ser um espaço em que elas podem criar uma história ou até descobrir que elas já têm uma história pra contar.

Todos concordaram.

- E com relação ao fato de virem novas pessoas participar do grupo, tá tudo bem? 
A CRIAÇÃO DE HISTÓRIAS NO CENTRO DE CONVIVÊNCIA: UM ENCONTRO ESPONTÂNEO POR MEIO DO PSICODRAMA

- É sempre bom dividir as nossas histórias com mais pessoas. $\mathrm{E}$ também ouvir novas histórias."

Ao final desse encontro, enquanto falávamos sobre se sentir parte de algo, Ziraldo, o criador do novo nome da Oficina, disse: "quando eu sair daqui, for pra outros lugares, eu vou dizer pra todo mundo que eu tive o prazer de estar numa sala como essa conversando com essas pessoas sobre as histórias da vida."

Pausando um momento a narração da Oficina, é possível fazer uma observação sobre o protagonismo, com esse exemplo de Ziraldo. Trata-se de alguém que constrói sua própria história, se emociona diante dela e que se permite ser mais objetivo e participativo na Oficina. Cabe aqui dizer que, em outras Oficinas, até em outros momentos para além desses espaços, Ziraldo era alguém bastante passivo, que sempre aceitava o que os outros sugeriam e pouco apresentava suas próprias ideias. Fazendo a analogia com o psicodrama, pode-se afirmar que o fato de Ziraldo estar experimentando o protagonismo na Oficina de Criação de Histórias já é um impulso para que desempenhe seus papéis de outra forma, ensaiando primeiro no espaço da Oficina.

A partir dessa época, a Oficina foi mudando. Outras pessoas chegaram e ensaiamos outras formas de criar histórias. Havia o pedido de algo que pudesse disparar as conversas. Por vezes eram figuras que cada um trazia de casa ou encontravam no próprio CECO, ou faziam ali mesmo, a punho.

Luís, por exemplo, um frequentador com deficiência visual, trouxe impresso o desenho de um cavalo em preto e branco, pois Ziraldo sempre falava em cavalos na Oficina e fora dela. Nesse dia, todos falavam do que pensavam quando viam aquela figura. Em seguida, sugeri que fechassem os olhos e imaginassem aquela figura, quais seriam as cores que tinham naquela paisagem, quais os movimentos que existiam nela e, se ela fosse um filme curto, quais as cenas que vinham antes e depois daquela imagem.

Nos encontros seguintes, as figuras levadas tinham temas que apareceram outrora nas histórias contadas até então, só que dessa vez, em vez de segurar as 
A CRIAÇÃO DE HISTÓRIAS NO CENTRO DE CONVIVÊNCIA: UM ENCONTRO ESPONTÂNEO POR MEIO DO PSICODRAMA

figuras e contar a história sentados, foi proposta a exposição da figura sob uma mesa improvisada e que todos escolhessem a que quisessem e criassem com ela sua história. Poderiam escolher com calma, se preparar, pensar com bastante calma e construir a história com o máximo de detalhes que conseguissem.

Nesse dia, as histórias tiveram muitos detalhes e a plateia, em lugar delimitado, observava com atenção.

Ao final desse encontro, eles disseram que gostavam de fazer parte daquela Oficina, pois se sentiam aceitos, que ali "a cabeça ficava melhor", "desenvolvia a mente" e que ao contar histórias do passado no presente se sentiam mais leves e mais vivos.

Nessa Oficina fica clara a importância da fase de aquecimento, em que há o melhor preparo do grupo para a dramatização, que acontece de maneira mais ativa. Até então, essas costumavam ser delimitadas pelo contato com a história trazida, o que se dava de maneira oral e não tinha diferença marcada entre uma fase e outra.

Nesse momento da Oficina, a dramatização já se dava de outra forma. O que antes acontecia de maneira predominantemente verbal, predominante no contexto grupal, agora já ensaiava uma passagem para o contexto psicodramático, o do "como se", da imaginação e da fantasia. Outra consequência foi a delimitação gradual do cenário, palco e plateia.

É comum que entre alguns psicodramatistas a dramatização seja associada quase que unicamente à ação, ao estereótipo de "ficar em pé no palco", sendo algumas vezes outras formas de dramatização desconsideradas, criticadas ou até mesmo negadas. Bustos (1992, p.59), no entanto, esclarece essa questão com as próprias palavras de Moreno: "é um erro acreditar que o psicodrama é uma cura de ação em oposição à cura da palavra da psicanálise [...]; não é a atividade em que produz o resultado".

Bustos (1992) então explica que são caminhos complementares, em que o 
A CRIAÇÃO DE HISTÓRIAS NO CENTRO DE CONVIVÊNCIA: UM ENCONTRO ESPONTÂNEO POR MEIO DO PSICODRAMA

falar constitui uma primeira forma de entrar em contato com uma situação, podendo ter como sequência a ação, agindo como complementar um do outro. Nesse sentido, o psicodrama propõe um método que concebe também a ação a fim de ultrapassar os possíveis limites em que a palavra esbarra, a racionalização, como um exemplo, e a necessidade de encontrar outros caminhos para as situações vividas.

A partir disso, o grupo, que havia passado por um período inicial em que as conversas se faziam mais presentes, pois esse era o primeiro contato que os participantes estavam tendo com essa nova situação, agora estava se sentindo mais à vontade para não só falar sobre as histórias, mas agir sobre elas.

$\mathrm{Na}$ Oficina que aconteceu posteriormente, Carlos escolheu a figura de um castelo e contou a história de um filósofo que era herdeiro de uma propriedade e não precisava trabalhar. Ficava apenas observando os seus trabalhadores e pensando em filosofia. Sentia-se igual aos trabalhadores, enquanto humano, só que até menor, pois os trabalhadores faziam algo de fato para mudar o mundo, enquanto ele não sabia nada sobre o vinho que era produzido na sua própria fazenda e nunca tinha provado. Contou que isso se assemelhava com sua vida, pois já houve uma época em que queria ser filósofo, mas sua mãe dizia que isso não dava dinheiro.

Em seguida, Maria afirmava o quanto era difícil para ela criar histórias, pois tinha muito problema "de cabeça", tinha dificuldade em aprender, e falou que mesmo crianças aprendiam com mais rapidez. Falou sobre como a vida inteira foi feita de boba, que as pessoas faziam o que quisessem com ela. Ela havia escolhido uma figura que tinha vários personagens de histórias medievais, sendo uma delas o bobo da corte; então pontuei que ela usou uma personagem da figura nessa história que contou.

Carlos ficou preocupado de que isso pudesse traumatizá-la e que ela não poderia sair da Oficina se sentindo dessa forma. Logo compartilhou que, quando mais novo, também já foi feito de bobo, mas conseguiu superar. Ela ficou muito satisfeita com o fato de ter percebido que 
conseguiu sim criar uma história, disse que gostou do grupo e que a história do filósofo tinha muitas palavras difíceis, que ele era muito inteligente, o que, por sua vez, deixou Carlos bastante contente, pois há tempos não ouvia isso sobre ele.

Nesse momento, ao final dos encontros, acontecia a fase de Compartilhar, em que era possível notar como aqueles encontros estavam funcionando para cada usuário e que também era um importante momento de vínculo no grupo, uma vez que em muitos momentos eles tanto tinham a experiência de se colocar para o grupo, quanto a de ouvir como o outro tinha sido afetado.

Em alguns encontros, os participantes definiam o formato da Oficina.

Em um desses, Nise preparou uma história e desde antes do início da Oficina informou o que gostaria de contar. Era uma história curta sobre um episódio de sua infância que envolvia um familiar que a chamava para cantar uma ciranda.

Em seguida, Maria conta que vivia deixada de canto quando criança, que era isolada e faziam bullying com ela. Pergunto se ela queria contar essa história de outra forma, mudando o que quisesse. Ela então conta que quando criança ficava emocionada ao ver o que tinha em seu jardim tão grande, que não sabia o nome, antes de descobrir que eram árvores. Ficava emocionada também com o vento e, à medida que ia contando isso, sua feição mudava, ficando muito empolgada. Falou que seu passado é muito triste, mas que prefere deixar para trás e contar essas histórias alegres.

Pergunto ao grupo se alguém tem uma sugestão de título para história dela e Ziraldo fala: "feliz daquele que tem uma história para contar".

Depois, Carlos cria uma história a partir de um fato real em sua vida, que envolvia uma procissão religiosa e histórias sobre santos, o que gera uma discussão bastante produtiva sobre santos, religião, o que leva ao São Nicolau, chegando no Papai Noel e, a partir daí, são partilhadas várias histórias sobre o Natal, infância, presentes e memórias. 
A CRIAÇÃO DE HISTÓRIAS NO CENTRO DE CONVIVÊNCIA: UM ENCONTRO ESPONTÂNEO POR MEIO DO PSICODRAMA

Ao final do encontro, esse mesmo participante comenta que até agora só tem construído histórias que se relacionam com seu passado e gostaria de treinar algo mais de improviso. Partindo desse pedido, Ziraldo então propõe que no próximo encontro cada um traga um desenho, só que um contará a história do desenho do outro para no final comparar a diferença das histórias.

Luís lembrou a sua dificuldade em desenhar, por ser cego, e levando isso em consideração combinamos que ficaria livre o que cada um traria, podendo ser desenho feito à mão, figuras impressas ou recortes.

Nesse dia, Nise, que até então trazia fatos de sua vida como tema de suas histórias e tinha dificuldade de acompanhar quando o grupo estava em um momento mais abstrato ou mais "imaginário", escolheu um desenho e criou uma história que se passava em um jardim muito bonito, que envolvia uma flor que amava ser admirada e um beijaflor que queria pousar na flor. O modo que ela contava era bastante "teatral", pois dava vozes e entonações diferentes aos personagens da história que, diferente das outras que ela contou até então, tinha vários personagens fictícios.

Ziraldo escolheu $\quad 0 \quad$ livro em braile que Luís havia trazido, mas não criou uma história a partir disso, pois afirmou não conseguir saber o que tinha ali dentro, então ele não tinha como criar algo.

Ao final do encontro, ele pediu que Luís lesse o livro e ficou impressionado. Todos ficamos curiosos e perplexos com a novidade.

Naquele dia, a única pessoa que conseguia enxergar era ele; todos nós estávamos cegos.

Em momentos como esse, o que se compreende como espontaneidade no Psicodrama fica ainda mais tangível.

Exatamente por meio da criação de histórias, os frequentadores dessa Oficina puderam viver momentos em que o imaginário tinha mais espaço e a realidade poderia ser vivida de outra forma, já que ali isso era possível. Maria já poderia lembrar a sua infância de outra forma além do bullying, Carlos poderia viver não só no passado, Nise poderia 
A CRIAÇÃO DE HISTÓRIAS NO CENTRO DE CONVIVÊNCIA: UM ENCONTRO ESPONTÂNEO POR MEIO DO PSICODRAMA

contar histórias reais da sua vida, e também criá-las, Ziraldo descobriu que tinha muitas histórias a ser compartilhadas com outras pessoas, e Luís contava, recontava e criava suas histórias favoritas.

Em outras palavras, os frequentadores dessa Oficina conseguiram atuar de outra forma em seus papéis, construindo e apresentando outras respostas, outras formas de desempenhar determinadas ações, desenvolvendo, assim, outro tipo de relação com aqueles ao seu redor.

Em relação ao papel de Diretora que desempenhei na Oficina, faço uso das palavras de Knobel (2000, p. 343) no que concerne às vertentes da direção, em particular a direção centrada na espontaneidade. Nesse caso, há o foco em provocar e pôr em ação estados espontâneos que se concretizam em "dramatizações coletivas de situações imaginárias, nas quais se podem experimentar o lúdico, o prazeroso, o novo e o estético".

O que foi descrito na citação de Knobel coincide com o que se deu na Oficina de Criação de Histórias, em que muitas das dramatizações passaram por personagens despertados pelas narrativas compartilhadas, tanto na dramatização que se dava por meio da fala, quanto na criação de histórias baseadas em figuras como Papai Noel, santos, Igreja.

Terminar uma história nunca parece ser tarefa fácil e terminar a Oficina também não. Encerramos da maneira que conhecíamos: compartilhando. Falamos sobre o que foi estar nessa Oficina, criar histórias e recriar nossa própria. O pedido foi feito para que ela continue no ano seguinte, mesmo sabendo que quem ali estava era quem tornava aquela Oficina única .

\section{Em vias de conclusão}


A CRIAÇÃO DE HISTÓRIAS NO CENTRO DE CONVIVÊNCIA: UM ENCONTRO ESPONTÂNEO POR MEIO DO PSICODRAMA

A Oficina de Criação de Histórias configurou-se como um espaço produtor de sentido, pois permitiu "encontrar modos de produção que singularizem existências, permitam o surgimento de processos criativos e, fundamentalmente, que legitimem a pluralidade da vida" (Galletti, 2004, p. 38).

Além de compartilharem comentários sobre as histórias trazidas, usuários viveram juntos a experiência de contar suas histórias de outras formas e de se verem criando histórias ao longo dos encontros, o que se traduz em um resgate da espontaneidade dessas pessoas.

Foi clara a mudança no modo de exercer o papel de protagonista dos usuários. Ao serem protagonistas da Oficina no ato de criar suas próprias histórias, exerciam esse papel que lhes é de direito, além do palco psicodramático, da Oficina, do Centro de Convivência: o papel de ser protagonista da própria vida. De contar sua história como desejo, criando e recriando quando necessário for.
Sabemos que os Centros de Convivência são espaços voltados para a inclusão, promoção de saúde por meio da promoção de lazer, cidadania e trabalho e, por que não, de afirmar um serviço que também promove a espontaneidade de seus frequentadores? $E$, quem sabe, a partir disso contribuir para a construção de relações mais saudáveis dentro do serviço, mas também fora, na vida dessas pessoas?

Martín (1996) afirma que o problema da saúde em um grupo, criado pela presença de pessoas que são tidas como "isoladas e inadaptadas", era importante para Moreno. Para ele, a exclusão dessas pessoas de um grupo não é a solução. A solução estaria mais bem firmada com a inserção em um grupo em que essas pessoas possam se reconhecer, estabelecer relações mais fidedignas (mais télicas) e assim desenvolver sua potencialidade de criador.

Nesse sentido, o Centro de Convivência pode ser palco desse grupo para essas pessoas "isoladas e anadaptadas", por sua potência em promover um espaço em que as pessoas até então excluídas de outros espaços da sociedade possam 
A CRIAÇÃO DE HISTÓRIAS NO CENTRO DE CONVIVÊNCIA: UM ENCONTRO ESPONTÂNEO POR MEIO DO PSICODRAMA

pertencer a um grupo, encontrar pessoas que possam estabelecer relações, escolher e ser escolhido. Pode ser, também, um serviço espontâneo e criativo que propõe em suas Oficinas espaços que ultrapassam as conservas culturais.
O Psicodrama, aqui, mostrou-se uma potente ferramenta de leitura e suporte para essa modalidade de serviço, com a realização de uma Oficina, cujo foco foi estabelecido na espontaneidade. O psicodrama pode oferecer ainda maiores reflexões sobre grupos, métodos ativos nas oficinas, dentre muitos outros...

\section{Referências}

Aleixo, Juliana M.P. \& Lima, Elizabeth M.F.A. (2017). Invenção e produção de encontros no território da diversidade: cartografia de um Centro de Convivência. Cadernos Brasileiros de Terapia Ocupacional, São Carlos, 25(3) 649-659.

Bondía, J. L. (2002) Notas sobre a experiência e o saber de experiência. Revista Brasileira de Educação, jan/fev/mar/abr, (19).

Bustos, Dalmiro Manuel. (1992). Novos rumos em Psicodrama. São Paulo: Editora Ática.

Ferigato, Sabrina Helena; Carvalho, Sérgio Resende \& Teixeira, Ricardo Rodrigues. (2016). Os centros de convivência: dispositivos híbridos para a produção de redes que extrapolam as fronteiras sanitárias. Cadernos Brasileiros de Saúde Mental, 8 (20), 79-100, 2016. 
A CRIAÇÃO DE HISTÓRIAS NO CENTRO DE CONVIVÊNCIA: UM ENCONTRO ESPONTÂNEO POR MEIO DO PSICODRAMA

Galletti, Maria Cecilia. (2004). Oficina em Saúde Mental: instrumento terapêutico ou intercessor clínico? Goiânia: Ed da UCG.

Gonçalves, C.S.; Wolff, J.R. \& Almeida, W.C. (1998). Lições de psicodrama: introdução ao pensamento de J.L.Moreno. 5.ed. São Paulo: Ágora.

Knobel, Anna Maria Antonia Abreu Costa. (2012). Estratégias terapêuticas grupais. In Nery, Maria da Penha \& Conceição, Maria Inês Gondolfo (Orgs.). Intervenções grupais: o psicodrama e seus métodos. São Paulo: Ágora, 2012. Malaquias, Maria Célia. Teoria dos Grupos e Sociatria. (2012). In NERY, Maria da Penha \& Conceição, Maria Inês Gondolfo (Orgs.). Intervenções grupais: o psicodrama e seus métodos. São Paulo : Ágora, 2012.

Martin, Eugenio Garrido. (1996). Psicologia do Encontro: J.L Moreno. São Paulo: Ágora.

Moreno, Jacob Levy. (1975). O Psicodrama. Tradução de Álvaro Cabral. São Paulo: Cultrix.

Oliveira, Rafael Barros de. (2016). Símbolos e Psicodrama. Fortaleza: Premius. Ramalho, Cybele M.R. (2010). Psicodrama e dinâmica de grupo. Aracaju, Editora IGLU.

Recebido em: 21/08/2020 Aprovado em: 15/08/2020 